\title{
Enhancing Teacher Creativity Using Digital Technology
}

\author{
Mgboro C.U.* Otubo F.A Uda H.U. \\ Department Educational Foundations, Ebonyi State University, Abakaliki
}

\begin{abstract}
The paper focused on how teachers enhance their creativity in secondary school using digital technology in secondary school studies. The study adopted the phenomenological approach by Gadamer and Csikszentmihalyi process of creativity. The paper presents an overview of teachers' lived experience that reveals the specific behaviour enhancing teacher creativity. The paper indentifies the factors enhancing teacher creativity while using digital technology. The paper concludes that teacher creativity is enhanced by the inner teacher creative personality characteristics, the external institutional forces, and the social environment where the teacher operates in. it means that using digital technology in secondary school studies allows teachers to be involved in the study process while the success of such teacher involvement is sustained by the creative personality traits and environment which support creativity.
\end{abstract}

Keywords: Teacher Creativity, Creative Personality, Digital Technology, Social Environment.

DOI: $10.7176 / \mathrm{JEP} / 10-27-03$

Publication date:September $30^{\text {th }} 2019$

\section{Introduction}

The expression of the teacher creativity while using digital technology is a subject of concern in the present dispensation of teaching and learning among secondary school students. This is because digital technology has changed how teachers source information for teaching, how they package the information to the students and the extent of personal life, social and cultural dimensions of information available for teaching and learning. Because of the changes observed above teachers are forced to independently decide and construct their own reality within the context of their personal-social and work environment. It is in the process of the personal learning and development that teacher creativity using digital technology becomes a necessary means of imparting knowledge to the students.

Man's ability to invent various technologies was revealed through promethean myth (Gadamer, 1999). Gadamer noted that promethean gave man fire, cultural skills and ability to help himself (creativity). Such creative activities are revealed in navigation, medicine, sculpture engineering, communication etc. The fire which symbolized 'entechnos Sophia Synpyri' (meaning knowledge of art and crafts) was given to man by promethean when he discovered that Epimetheus did not provide man with survival skills. Fire and tools were responsible for human survival and improvement of human conditions. According to Sliogeriene and ValunaiteOleskeviciene (2017) with fire and tools man was able to constantly invent, reinvent technology and being reinvented by technology.

The current teaching and learning realities demand fast changes which require an increasing adaptability from teachers and creative approach to the technologically wired educational environment. The reality is expressed by McLuhan (2003) who noted that times of mechanistic and linear philosophy were over, and it is replaced by the simultaneity and concentricity of the digital technology. Teachers therefore need to join the world, however, their success is hinged on their personal expression of creativity.

Perhaps it was the understanding of the above challenges that led the Federal Government of Nigeria in 2012 to announce the linking of some Federal Universities to the internet. The aim was to improve the quality of education and bring the students into a lifelong learning through the creativity of teachers who use digital technology. Unfortunately no such concerted effort was made for secondary and primary education which are the foundations of education. The Federal Government in 2010 (FME, 2010) had introduced the National policy on Information and Communication Technology (ICT) in education. The aim was to provide guidance in the process of ICT in education. It will foster the production of grandaunts who will survive in the contemporary digital society.

Digital technology which involves electronic teaching (e-teaching) and electronic learning (e-leaning) utilizes technology to deliver, interact or facilitate information. E-teaching and e-learning offer students increased access to learning opportunities, convenience of time and place, making available a greater variety of learning resources, improved opportunities for individual learning and emergence of more cognitive tools (Ugwuogo, 2011). Digital technology is a problem solving process which is focused on improving quality of human life (Yang, 2003). It can be viewed as a frame of mind and ones ability to operate critical thinking, it is the understanding that solutions to current problems are only in a tentative form (Mgboro, 2012). The existence and frequency of problem solving and critical thinking skills in digital technology makes it unavoidable partner in enhancing teacher creativity. 
The issue is that most researches on enhancing teacher creativity using digital technology were conducted only within the western context. Such contexts examined more effects of electronic environment on various forms of creativity: idea generation, problem solving, expressive writings and artistic production (Yang, 2003; DeRosa, Smith, \& Hantula, 2007). The research field of digital technology in the Western society embraces unlimited possibilities for the expression of teacher creativity. Some of the researches are viewing digital technology as disruptive and contaminating education and human minds (Yang, 2003).

Creativity is central to social/economic development but little research seem to be carried out in the field in developing countries especially with regard to how it can be driven using digital technology. The $21^{\text {st }}$ century education system is focused to transform the educational objectives, curriculum, pedagogies and assessment in order to equip students with the work requirements, citizenship education and self actualization. Digital technology is therefore a means of encouraging, stimulating, and assisting teachers to enhance their creativity towards achieving the above goals.

The purpose of the paper is to examine the phenomenon of enhancing teacher creativity expression while using digital technology in secondary schools. The study of creativity and digital technology is based on teachers lived experience while using digital technology for teaching and learning in secondary schools. The research question focused on how teachers perceive their creative expression using digital technology for teaching and learning in secondary schools. How does the social environment of secondary school enhance teacher creativity? What aspects of teacher experience reveal the elements that enhance teacher creativity while using digital technology? How do the elements enhance teacher creativity?

The research helps one to better understand how teacher creativity is revealed using digital technology and how teachers make sense of their creativity expression through their own lived experience.

\section{Concept and approaches to Creativity}

Creativity is the ability to generate new and valuable ideas, adapt to change, and to envision and bring about change (Runco, 2004; Mgboro, 2012). It is a complex multifaced process which has little conceptual clarity (Mgboro, 2004). It is closely associated with artistic, spiritual activities, however modern scholars (Sliogeriene \& Valunaite-Oleskeviciene, 2017) extend the concept and focus more on the practical and professional aspects. The characteristics of creative individual as indicated by the humanistic philosophers include freedom, courage, self confidence, seeing the world as a child. The approach to creativity research has focused on different paradigm shifts: mystical, psychoanalytic, pragmatic, cognitive, social-personality, interdisciplinary and the confluence approach (Sliogerien \& Valunaite-Oleskeviciene 2017). The aim of the different paradigm is to unveil the various dimensions of creativity. The confluence approach specifically integrates the different aspects with purpose of understanding the broader impact of creativity context.

According to Csikszentmihaly, $(1996,2003)$ creativity is the outcome of interaction among the individual, the social environment and the culture in which they operate. The individual houses the ideas for creativity, defines the need for creativity, directs the changes and how to improve creativity. In the context of this study the individual is the teacher whose ideas work to apply new technologies creatively. The social environment includes people (school authorities, teachers, students and parents) who promote and accept the creative initiatives of the teacher. The culture, the relatively established pattern of performance masterminded by the authorities and the reaction of the entire school shape the way of life within school system.

It is noteworthy that qualities of self confidence, wiliness to experiment and take risks, interest in innovation are some of the creative personality qualities identified in social-personal approach theories by Amabile (1983). Amabile further outlined independent thinking, self confidence, interest in complex phenomena, aesthetic needs as characteristics of teacher creativity. Three levels of creativity were also identified within the social environment. These are the recognition level where new ideas are provided, developed, promoted, supported and implemented; the administrators approach and promotion level within the school; the peer support, collaboration, openness to innovation and change, and relationship based on trust and mutual assistance.

Creativity is important for self expression and satisfaction as one can witness in music artworks and industrial products. It makes the individual to create meaning in life, while for industries, in spite of the changing market forces, continue to learn and provide employment opportunities. Specifically Cropley (2008) outlined characteristics of creativity as novelty, efficiency, ethical, flexibility or originality and fluency.

\section{Research Method}

The study employed phenomenological interview in order to get the authentic information on the experience of the teacher using digital technology in schools. The semi-structured interviews is recorded for deeper investigation of how teacher creativity is enhanced by digital technology. The respondents through interview raised important issues and presented their own versions of how digital technology enhance teacher creativity. The researcher collected empirical data through communication with the teachers (Ricoeur 2000) Ricoeur had noted that communication helps one to express the personal experience which is not possible to be fully 
expressed to someone else. Communication therefore transfers the different dimensions practically experienced by one person to another person. Phenomenological interview therefore gains meaning by relying on the semistructured interview as the true source revealing practical experience of the teachers as they try to enhance their creativity while using digital technology.

The study used teachers from Hope High International school, Abakaliki in Ebonyi State. The focus was on how the teachers perceive and identify their creativity while using digital technology. The teachers from the school were chosen because the school has the equipment which teachers also use for teaching and learning by students. The teachers also appear to have insights about their creativity expression while using digital technology. Criterion-based sampling was used. Such criteria include, nature of work and experience of teachers using digital technology. At least the teachers must have worked in the school for five years using digital technology. Based on the above criteria ten teachers participated in the semi-structured interviews. The interviews lasted for 50 minutes per a person. It means that 8 hours were used to record the interview materials.

The ten teachers were introduced to the purposes of the research. They voluntarily made up their mind to participate in the study. In order to preserve the confidentiality of the teachers' personality their names were not used.

Open ended questions were used to elicit stories from the teachers about their experience while using digital technology. The open-ended questions were constructed around the main question which focused on teachers' experiences about enhancing teacher creativity using digital technology. The open-ended questions were adapted from Sliogeriene and Valunaite-Oleskeviciene (2017). For instance, could you outline your most memorable experience about how you experienced creativity using digital technology while teaching? Such questions were followed by more specific questions such as, identify the feelings involved, outline details of what your experiences were; how did you experience the environment during the episode? The questions allowed for deep investigation about teacher creativity. Questions could be changed or not asked at all where the teacher gave detailed information about his experience either before or after the questions were asked. The process enabled the teachers to raise issues of importance to them and also present their own side of experience about teacher creativity using digital technology.

The recorded interview was transcribed, read many times in order to understand fully the meaning as a whole. Through the above process the researcher formulated the understanding which guided the structural analysis (Sliogeriene \& Valunaite-Oleskeviciene, 2017). According to them structural analysis helps the researcher to validate and adjust naïve interpretation in order to get meaning of views expressed. Meaningful units are thereby identified (a piece of information carrying one meaning) it could be a part of sentence, a full sentence or few sentences. The meaningful units were abstracted and condensed to form sub-themes. The sub themes were clustered into themes and the themes were later joined into the main theme of enhancing teacher creativity. Those meaningful units and themes were further used in compiling the textual description. The meaning of a number of different contexts were summarized, logical relationships were identified in order to have a clear picture of teacher creativity based on the interpretation from the views of the teachers.

\section{Findings}

The study focused on enhancing teacher creativity while using digital technology in secondary schools. Three things were discovered to enhance teacher creativity-the inner creative personality characteristics of the teacher, the influence of the institution, and the social environment where the teacher operates. The experience of the teachers reveal that two approaches are involved in enhancing teacher creativity-stimuli coming from other teachers (external social factors) during the process of exchanging and implementing ideas and institutional support (principals policies and programmes). The second approach are the personal qualities of the teacher. The above approaches are presented in the table below: 
Table 1: Enhancing Teacher Creativity

\begin{tabular}{|c|c|c|c|}
\hline $\mathbf{S} / \mathbf{N}$ & Meaningful Units showing teacher creativity (TC) & Subtheme & Theme \\
\hline 1 & The sincere example of colleagues was really inspiring & Colleague example & \\
\hline 2 & During seminars staff shared their own ideas & $\begin{array}{l}\text { Colleagues sharing } \\
\text { ideas }\end{array}$ & Social environment \\
\hline 3 & $\begin{array}{l}\text { It was teaching and training my colleagues that made } \\
\text { me to actively use digital technology }\end{array}$ & Training colleagues & \\
\hline 4 & $\begin{array}{l}\text { A lot of things were presented during the seminar and } \\
\text { training session. }\end{array}$ & $\begin{array}{l}\text { Information acquired } \\
\text { at seminar }\end{array}$ & $\begin{array}{l}\text { Exchanging and } \\
\text { implementing ideas }\end{array}$ \\
\hline 5 & $\begin{array}{l}\text { I took part in courses where information on finding } \\
\text { free programmes were given. }\end{array}$ & $\begin{array}{l}\text { Information acquired } \\
\text { at course }\end{array}$ & \\
\hline 6 & $\begin{array}{l}\text { I get some ideas while reading books; I hear what } \\
\text { people say. }\end{array}$ & Ideas from literature & \\
\hline 7 & $\begin{array}{l}\text { Some of my ideas on using digital technology come } \\
\text { from technical experiences, from perceiving logic of } \\
\text { the programme }\end{array}$ & $\begin{array}{l}\text { Ideas acquired } \\
\text { through experience }\end{array}$ & \\
\hline 8 & $\begin{array}{l}\text { When I do not use the various digital technologies } \\
\text { actively I seem to forget them. }\end{array}$ & $\begin{array}{l}\text { Active application of } \\
\text { digital technology }\end{array}$ & \\
\hline 9 & $\begin{array}{l}\text { I started using digital technology because the school } \\
\text { forced me to use them }\end{array}$ & Impact of the school & Institutional impact \\
\hline 10 & $\begin{array}{l}\text { The school encourages the use of digital technology } \\
\text { hence we feel a sense of creativity }\end{array}$ & & \\
\hline 11 & $\begin{array}{l}\text { Because of the pressure on me, because I had to do } \\
\text { everything myself I was forced to use digital } \\
\text { technology. }\end{array}$ & & \\
\hline 12 & $\begin{array}{l}\text { It was in the work place that teachers started using } \\
\text { digital technology since they want to perform on their } \\
\text { job }\end{array}$ & & \\
\hline 13 & $\begin{array}{l}\text { I can handle high risk situations, am not afraid of } \\
\text { losing, taking some time to correct everything, and } \\
\text { taking responsibility }\end{array}$ & Ability to take risks & $\begin{array}{l}\text { Creative personal } \\
\text { characteristics }\end{array}$ \\
\hline 14 & $\begin{array}{l}\text { If things are difficult, whether I know it or not, I keep } \\
\text { trying or ask for help }\end{array}$ & Ability to experiment & \\
\hline 15 & I still experiment with various digital technologies & Ability to experiment & \\
\hline 16 & $\begin{array}{l}\text { Sometimes technologies fail me, but I continue to solve } \\
\text { the problems }\end{array}$ & $\begin{array}{l}\text { Ability to solve } \\
\text { problem creatively }\end{array}$ & \\
\hline 17 & $\begin{array}{l}\text { When I get interested and enthusiastic I share } \\
\text { information with others }\end{array}$ & Enthusiasm & \\
\hline 18 & $\begin{array}{l}\text { I understand a lot of information exists on the internet, } \\
\text { so I am ready to accept changes. }\end{array}$ & Openness to changes & \\
\hline
\end{tabular}

Adapted from Evoking teacher creativity by Sliogeriene and Valunaite- Oleskeviciene (2017).

Based on the table above the external factors enhancing teacher creativity while using digital technology in secondary schools include such themes as the social environment which represents, influence of teachers' colleagues (examples from colleagues, shared ideas, and help given to the colleagues). Ideas can be acquired directly from colleagues, or through seminars, courses and other training sessions.

Another source of ideas which help to enhance teacher creativity is the teacher personality. This is evidenced when the teacher reflects and summarizes his experiences in working with a variety of programs and equipment. While the colleagues encourage the use of digital technology, the teacher is also active while using them, he gets to a point where he can now say, "I have mastered it".

As it affects how the teachers experience the impact of the institution on enhancing their creativity, it was revealed that the school encourages them to use digital technology (TC10). Some teachers, however, perceived their using digital technology as being forced on them by the school, "I started using digital technology because the school forced me (TC9)". Some other teachers reported that the pressure and stressful situation they found themselves in made them to discover the creativity in them. "Because I had to do everything myself, I was forced to use digital technology (TC 11). Stressful events can lead to "fight" or flight" situations. Teachers, creativities are variously affected by trainings, seminars, literatures $(\mathrm{TC} 4,5,6)$. The teachers are exposed to colleagues example, technical experience acquired at the work place and encouraging socio-emotional climate of the school.

The personal characteristics of teachers which are revealed as teachers use digital technology include risk taking abilities which enable the teacher to be confident in the course of employing test, ability and willingness 
to experiment (TC13 \& TC15), ability to solve problems which enable teachers to employ digital technology when other technologies fail (TC16). Other personal characteristics are deep interest in digital technology and enthusiasm to apply them (TC17).

\section{Discussion of Findings}

The study revealed that for teachers to enhance their creativity using digital technology there has to be the creative personality traits of the teachers, and environment supportive of creativity. Utilization of digital technology in the classroom by teachers enhances teachers' creativity because all the skills that lead to creative development, nurturing and production are encouraged and strengthened. Using digital technology challenges the teacher to take responsibility for their work, to absorb shock, take risk and engage in tasks, try new techniques without fear of error. Furthermore, individual differences in students learning might be better handled by teachers using digital technology. This is because groups and individuals at risk (dropout, slow and fast learners) might be better identified, and digital technology forms an innovative catalyst for creativity in life long learning (Mgboro, 2013). It is true some teachers revealed that using digital technology was forced on them by the school authority (pressure from the school) they however, noted that the personality traits of risk taking, flexibility, willingness to experiment, enthusiasm, openness to innovation enabled them to use digital technology successfully during teaching and learning. Mgboro and Eke (2015) had mentioned the above creative personality characteristics as necessary personal creative qualities.

In line with the above creative personality characteristics two dimensions of enhancing teacher creativity using digital technology in secondary schools were identified in the present study. These are internal and external dimensions. The internal dimensions were already identified in the preceding paragraph. The external dimensions include colleagues' impact, idea sharing, active implementation, and institutional impact which might come in form of encouragement or pressure. The above external dimensions interact with what CSikszentmihalyi $(1996,2003)$ described as the systems theory perspective on creativity-the interaction of the individual, social environment and culture. The external dimension identified in the present study relate to the social environment (colleague impact) while the culture relate to the institutional impact.

\section{Conclusions}

The external factors (colleagues' impact, new ideas to be tried out) are stimulated by internal factors (risk taking, willingness to experiment, openness to innovation). The above features are revealed as teachers use digital technology while teaching in secondary schools. Teachers' creativity is enhanced by their colleagues, sharing ideas and performance expectations which are dictated by the school. The importance of creative personality characteristics which combine with the external issues were highlighted.

\section{Recommendations}

Based on the findings of the study the following recommendations were made.

(i) Teachers' attitude and perception towards using digital technology in the classroom should be addressed. This will be done by training them on the use of digital technology for teaching and learning.

(ii) Since creativity thrives in an atmosphere of freedom with little restriction the school time table should be restructured to enable teachers and student gain from digital technology.

(iii) Digital technology should focus on promoting the local content strategies which entails using local language to encourage cultural, indigenous technology and consequently economic growth.

(iv) Government should address electricity challenges in the educational system. Most schools in the country do not have electricity, therefore teaching and learning using digital technology is still a dream that appears unattainable.

\section{References}

Amabile, TM. (1983). The social psychology of creativity. Series Springer series in social psychology. Kidd, R.F. (Ed). New York: Springer-Verlag.

Cropley, A.J. (2008). Creativity in education and learning: A guide for teachers and educators. London New York: Routludge/falmer.

CSikszentmihalyi, M. (1996). Creativity: Flow and the psychology of discovery and invention. New York:Routledge/Palmer.

CSikszentmihalyi, M. (2003). The domain of creativity. In Runco, M.A. \& Albert, R.S. (Eds). Creativity research handbook 3. cruskill NJ: Hamption press.

DeRosa, D.M., Smith, C.L. \& Hantula, D.A. (2007). The medium matters: mining the long-promised merit of group interaction in creative idea generation tasks in meta-analysis of the electronic group brainstorming literature Computers in human behaviour 23,(3) 1549-1581.

Federal Republic of Nigeria (2010). Information and communication technology in education. Abuja: Federal 
Ministry of Education.

Gadamer, H.G. (1999). Istorija, Menas, Kalba. Vilnius: Bathos Lankos.

McLuhan, M. (2003). Kaip suprati medijas: Zmigatesiniai Vilnius: Bathos Lankos.

Mgboro, C.U. (2004). Perceived parental acceptance rejection as correlate of creativity. Unpublished Ph.D thesis. UNN.

Mgboro, C.U. (2012). Enhancing creativity through information communication technology (ICT) Journal of assertiveness 5(1) 69-76.

Mgboro C.U, \& Eke, N.A. (2015). Adolescent students perception of supportive classroom environment for creativity in secondary schools of Ebonyi State. Academic discourse: an international journal 8(1) 137-142.

Ricoeur, P. (2000). Interpretacijos teorija: diskursas ireiksmes perteklius. Vilnius: Bathos Lankos

Runco, M.A. (2004). Creativity. Annual review of psychology, 55(1) 657-687.

Sliogeriene J., Valunaite-Oleskeviciene, G. (2017) Evoking teacher creativity while using social media. Creativity Studies 10 (1) 84-96.

Ugwuogo C.C. (2011). Status of e-teaching and e-learning in Nigeria colleges of education unpublished Ph.D thesis Ebonyi State University, Abakaliki

Yang S.C. (2003). Computer-mediated history learning spanning three centuries project. Computer in human behavaiour 19(3) 299-318. 